\title{
TINGKAT KEAMANAN MINUMAN INFUSED WATER DENGAN DIVERSIFIKASI PENYIMPANAN YANG BERBEDA
}

\author{
Surati Surati*) ; Nurul Qomariah \\ Jurusan Analis Kesehatan Poltekkes Kemenkes Semarang \\ Jl. Woltermonginsidi No 115, Pedurungan, Semarang
}

\begin{abstract}
Abstrak
Minuman infused water adalah air putih yang telah diberi tambahan potongan buah-buahan sehingga air tersebut memberikan sensasi rasa air tertentu dan bermanfaat bagi kesehatan. Minuman infused water mulai dikenal dan dikonsumsi oleh sebagian masyarakat indonesia karena proses pembuatannya sangat mudah, menggunakan buah-buahan lokal dan infused water bermanfaat bagi kesehatan karena mengandung vitamin dan mineral. Tujuan penelitian ini untuk mengetahui tingkat keamanan minuman infused water dengan diversifikasi penyimpanan yang berbeda. Kemudian dicocokan dengan Standar Nasional Indonesia (SNI) 7388 : 2009. Adapun manfaat penelitian ini adalah dapat menambah daftar minuman yang sehat dan bergizi. Ekperimen dilakukan dengan rancangan acak lengkap (RAL), Analisis data untuk mengetahui adanya pengaruh penyimpanan yang berbeda terhadap keamanan minuman infused water maka dilakukan uji kenormalan data dengan Shapiro Wilk. Data terdistribusi normal maka menggunakan uji Anova. Kode sampel (AP, BP, CP, AD, BD, CD) Pemeriksaan angka lempeng total (ALT) memenuhi syarat dalam SNI No 01-3553-2006. Kemudian dilakukan uji penduga, uji penegas dan uji angka paling mungkin (APM) memenuhi syarat dalam SNI 7388:2009. Hasil pemeriksaan Angka Lempeng Total dan Most Probable Number Coliform semua sampel telah memenuhi syarat Standar Nasional Indonesia (SNI) maka minuman infused water layak untuk dikonsumsi.
\end{abstract}

Kata kunci: Tingkat keamanan ; Minuman ; Infused water

\section{Abstract}

[SAFETY LEVEL OF INFUSED WATER DRINKS WITH DIVERSIFICATION OF DIFFERENT STORAGE] Infused Water beverages is water that has been given an extra piece of fruits that give the sensation of flavour and have much benefits for health. Infused Water became known and consumed by most people of Indonesia because the manufacturing process is very easy, using local fruits and have much benefits because it contains vitamins and minerals. The purpose of research is to determine the level of security of Infused Water beverages with different storage diversification and then matched with Standar Nasional Indonesia (SNI) 7388:2009. As for the benefits of this research is to be able to add a list of healthy and nutrition beverages. Types of research is experiment with a completely randomized design (RAL), data analysis to determine the effect of different storage towards security of Infused Water beverages then tested with normality of data using Shapiro Wilk. After the data have normal distribution then using Anova test. Research result: Sample code (AP, BP, $\mathrm{CP}, \mathrm{AD}, \mathrm{BD}, \mathrm{CD}$ ) of Angka Lempeng Total (ALT) examination qualified in Standar Nasional Indonesia (SNI) No. 01-3553-2006. There after do the estimators test, a confirmation test and Angka Paling Mungkin (APM) test that has been qualified in SNI 7388:2009. Examination result of Angka Lempeng Total (ALT) and Most Probable Number Coliform all samples comply the requirements of SNI, accordingly infused water has been decent for consumption.

Keywords: The level of security ; Drink; Infused Water

\section{Pendahuluan}

Air merupakan salah satu komponen yang dibutuhkan dalam kehidupan manusia dan merupakan sumber kehidupan, ketersediaan air

*) Surati
E-mail: suniahyusuf@ymail.com dari segi kualitas maupun kuantitas harus dijaga. Semua makluk hidup membutuhkan air untuk dikonsumsi, sehingga air mempunyai manfaat yang sangat banyak antara lain adalah untuk makan dan minum, air untuk kebutuhan setiap hari (mandi, mencuci). Fungsi air bagi tubuh antara lain sebagai pelarut dari berbagai jenis 
bahan makanan seperti karbohidrat, asam lemak dan vitamin, bahan-bahan yang larut didalam darah diangkut keseluruh tubuh dan dipergunakan sesuai dengan fungsinya. Air sebagai pengatur suhu tubuh, air berperan penting untuk mendistribusikan panas yang ditimbulkan oleh metabolisme tubuh dan di ubah menjadi keringat. Air sebagai sumber mineral. Air mineral digunakan sebagai obat seperti untuk diet dan untuk menyembuhkan penyakit tertentu, terutama penyakit kekurangan mineral air di dalam tubuh, misalnya kekurangan iodium dan kalsium (Lancar Prayoga, 2014).

Berdasarkan peraturan menteri

kesehatan Republik Indonesia Nomor 907/MENKES/SK/VII tahun 2002, yang dimaksud air minum adalah air yang melalui proses pengolahan atau tanpa pengolahan yang memenuhi syarat kesehatan dan dapat langsung diminum. Adapun syarat pengawasan air minum meliputi : Bakteriologi, Kimiawi, radio aktif dan fisika (Fardiaz, 1989). Pengertian air minum dapat dilihat pula dalam Keputusan Menteri Perindustrian dan perdagangan Republik Indonesia Nomor: 651 /MPP /Kep /10 / 2004 tentang: Persyaratan Teknis Depot Air Minum dan Perdagangannya. Dalam keputusan tersebut disebutkan bahwa air minum adalah air baku yang telah diproses dan aman untuk diminum (Kep Men Kes RI, 2002). Air minum yang ideal harusnya jernih, tidak berwarna, tidak berasa dan tidak berbau, serta tidak mengandung kuman patogen dan zat kimia yang dapat mengganggu fungsi tubuh (Suprihatin, 2003).

Air minum adalah salah satu kebutuhan utama bagi manusia. Air minum adalah air yang melalui proses pengolahan atau tanpa proses pengolahan yang memenuhi syarat kesehatan dan dapat langsung diminum. Air minum yang baik adalah air yang memenuhi persyaratan seperti bebas dari cemaran mikroorganisme maupun bahan kimia yang berbahaya dan tidak berasa, berwarna, dan berbau (Slamet, 1994; Kepmenkes, 2002). Penyediaan air bersih selain kuantitasnya, kualitasnya pun harus memenuhi standar yang berlaku. Karena air baku belum tentu memenuhi standar, maka dilakukan pengolahan air untuk memenuhi standar air minum. Pengolahan air minum dapat sangat sederhana sampai sangat kompleks tergantung kualitas air bakunya. Apabila air bakunya baik, maka mungkin tidak diperlukan pengolahan sama sekali. Apabila hanya ada kontaminan kuman, maka disinfeksi saja sudah cukup, tetapi apabila air baku semakin jelek kualitasnya maka pengolahan harus lengkap (Slamet, 1994). Diperlukan empat persyaratan pokok air minum: 1. Persyaratan biologis, berarti air minum itu tidak boleh mengandung mikroorganisme.

2. Persyaratan fisik, kondisi fisik air minum terdiri dari kondisi fisik air pada umumnya, yakni derajat keasaman, suhu, kejernihan, warna, dan bau.

3. Persyaratan kimiawi menjadi penting karena banyak sekali kandungan

kimiawi air yang memberi akibat buruk pada kesehatan karena tidak sesuai dengan proses biokimiawi tubuh.

Air yang bersih harus mempunyai kualitas yang tinggi mencakup tiga syarat yaitu secara fisika, kimiawi dan biologis untuk mencegah timbulnya penyakit, kita setiap saat minum dengan air, air yang kita konsumsi harus memenuhi persyaratan baku mutu air sesuai dengan standar nasional indonesia (SNI). Syarat fisika antara lain air harus jernih atau tidak keruh, air tidak berwarna, air tak berasa atau rasanya tawar, air tidak berbau, temperaturnya normal dan tidak mengandung zat padatan. Syarat kimia antara lain $\mathrm{pH}$ netral,tidak mengandung bahan kimia beracun, tidak mengandung garam atau ion-ion logam, kesadahan rendah dan tidak mengandung bahan organik. Syarat bakteriologi antara lain air tidak mengandung bakteri patogen, misalnya bakteri golongan coli, salmonella typhy dan air tidak boleh mengandung bakteri non patogen seperti coliform. Manusia memerlukan air untuk minum, Minuman bermacam - macam jenisnya, contoh air mineral yang dikemas dengan berbagai macam bentuk dan beragam merk, Air mineral saja tidak cukup sehingga muncullah produk minuman berasa seperti, teh, kopi, jus, sprit, soda dan minuman infused water.

Minuman infused water adalah air putih yang telah diberi tambahan potongan buahbuahan atau herbal (jahe, kayu manis, dll) sehingga air tersebut memberikan sensasi rasa air tertentu dan bermanfaat bagi kesehatan. Bahan dasar pembuatan minuman infused water adalah air sehingga air yang digunakan harus diperhatikan kualitasnya. Buah - buahan sebelum digunakan dicuci agar bersih dari berbagai kotoran, kulit dan buah langsung digunakan pada proses pembuatan infused water, buah- buahan tersebut di iris secara melintang kemudian dimasukkan dalam satu 
liter air yang ditempatkan dalam botol dan disimpan dalam kulkas minimal 2 jam agar buah -buahan tersebut mengeluarkan vitamin dan mineral dan menimbulkan sensasi rasa yang berbeda. Minuman infused water mulai dikenal dan dikonsumsi oleh sebagian masyarakat indonesia karena proses pembuatannya sangat mudah, buah-buahan mudah di dapat dan infused water bermanfaad bagi kesehatan karena minuman infused water mengandung vitamin dan mineral. Vitamin dan mineral pada infused water berasal dari buah buahan tersebut.

Minuman infused water merupakan salah satu minuman yang berasa dan sangat mudah dalam proses pembuatanya maka perlu di analisis kualitas mikrobanya, untuk mengetahui kualitas mikroba pada minuman infused water tersebut harus berpedoman pada badan standar nasional (BSN) yang mengaju pada standar nasional indonesia (SNI) 7388 : 2009, setelah diketahui kualitas mikrobiologinya sehingga minuman infused water tersebut aman dikonsumsi dan perlu diketahui kandungan vitamin dan mineral. Berdasarkan uraian diatas peneliti ingin meneliti tentang tingkat keamanan minuman infused water dengan diversifikasi penyimpanan yang berbeda.

\section{Metode}

Penelitian ini termasuk penelitian jenis eksperimen yang digunakan untuk menguji hipotesis yang ada sehingga diketahui pengaruh antar variabel. Rancangan percobaan yang digunakan dalam penelitian ini adalah Rancangan Acak Lengkap ( RAL ) dengan variabel bebas yaitu minuman infused water dengan diversifikasi penyimpanan yang berbeda sedangkan variabel terikatnya yaitu bakteri pada infused water. Penelitian ini membuat tiga produk infused water kemudian dilakukan penyimpanan yang berbeda. Untuk mendapatkan jumlah unit sampel menggunakan rumus Gomez and Gomez (Hanafiah, 1995). Jadi pengulangan yang digunakan pada tiap-tiap perlakuan sampel sebanyak 3 kali, sehingga sampel yang akan dibuat 18 unit sampel.

\section{Hasil dan Pembahasan}

Sampel penelitian merupakan infused water yang disimpan pada suhu yang berbeda. Sampel penelitian sebanyak 3 unit sampel yaitu infused water lemon, infused water lemon stoberi daun mint dan infused water lemon timun daun mint yang disipan pada suhu ruang dan suhu dingin / refrigerator sehingga diperoleh 6 unit sampel yaitu AP, BP, CP, AD, $\mathrm{BD}$, dan CD. Kemudian sampel dilakukan pemeriksaan ALT (Angka Lempeng Total) dan MPN ( Most Probable Number) Coliform secara duplo.

Pemeriksaan sampel dilakukan pada bulan September tahun 2016. Sampel infused water dimasukkan dalam botol air minum $500 \mathrm{ml}$ dan disimpan pada suhu yang berbeda (suhu ruang dan refrigerator) selama 4 jam kemudian dilakukan pemeriksaan. Pada uji ALT, sampel diinokulasikan pada media PCA dengan metode Spread Plate. Sedangkan untuk Uji MPN, sampel diinokulasikan ke dalam media Lactose Broth. Hasil positif pada media lactose broth selanjutnya diinokulasikan ke dalam media Brilian Green Lactose Broth dan dilanjutkan dengan pengamatan hasil pemeriksaan. Penelitian ini dilakukan pada bulan September 2016 di Laboratorium Mikrobiologi Kampus III Jurusan Analis Kesehatan Poltekkes Kemenkes Semarang dengan sampel penelitian yang digunakan adalah infused water dengan suhu penyimpanan berbeda yaitu pada suhu ruang dan suhu refrigerator. Hasil penelitian diperoleh data sebagai berikut :

Tabel 1. Hasil Uji ALT Minuman Infused Water suhu ruang $\left(25^{\circ} \mathrm{C}\right)$

\begin{tabular}{ccccc}
\hline No & Kode & ALT & Std & Ket \\
\hline 1 & AP & $8 \times 10^{3}$ & $1 \times 10^{5}$ & MS \\
\hline & & $6 \times 10^{3}$ & $1 \times 10^{5}$ & MS \\
\hline 2 & BP & $8 \times 10^{3}$ & $1 \times 10^{5}$ & MS \\
\hline 3 & CP & $7 \times 10^{3}$ & $1 \times 10^{5}$ & MS \\
\hline & & $9 \times 10^{3}$ & $1 \times 10^{5}$ & MS \\
\hline
\end{tabular}

Keterangan: MS (Memenuhi Syarat). Standar menurut SNI No 01-3553-2006



Grafik 1. Angka lempeng total (ALT) infused water pada suhu ruang $\left(25^{\circ} \mathrm{C}\right)$ Infused water dengan penyimpanan suhu refrigenerator $\left(5^{\circ} \mathrm{C}\right)$ setelah 4 
jam dilakukan pemeriksaan angka lempeng total (ALT).

Hasil pemeriksaan ALT sebagai berikut :

Tabel 2. Hasil Uji ALT Infused Water pada suhu refrigenerator $\left(5^{\circ} \mathrm{C}\right)$

\begin{tabular}{ccccc}
\hline No & Kode & Alt & Std & Ket \\
\hline 1 & AD & $4 \times 10^{3}$ & $1 \times 10^{5}$ & MS \\
\hline & & $1 \times 10^{3}$ & $1 \times 10^{5}$ & MS \\
\hline 2 & BD & $3 \times 10^{3}$ & $1 \times 10^{5}$ & MS \\
\hline & & $2 \times 10^{3}$ & $1 \times 10^{5}$ & MS \\
\hline 3 & CD & $2 \times 10^{3}$ & $1 \times 10^{5}$ & MS \\
\hline & & $1 \times 10^{3}$ & $1 \times 10^{5}$ & MS \\
\hline
\end{tabular}

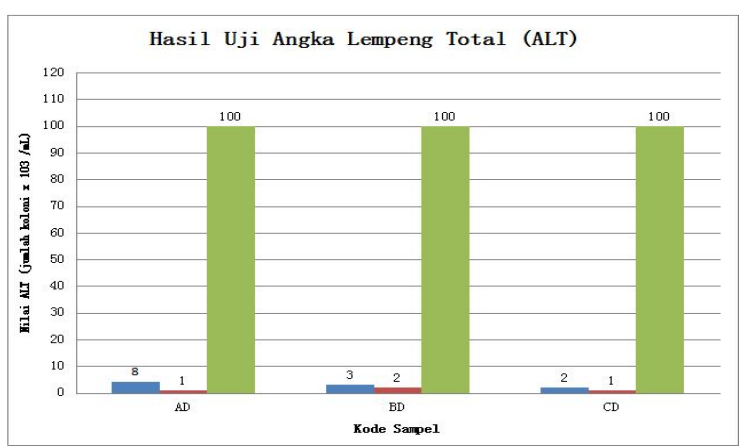

Grafik 2. Angka lempeng total (ALT) infused water pada suhu refrigenerator $\left(5^{\circ} \mathrm{C}\right)$.

Berdasarkan tabel 1 dan 2 serta grafik 1 dan 2 . Sampel yang digunakan adalah sampel infused water yang penelitiannya dilakukan secara duplo. Pada hasil diatas disebutkan bahwa sampel AD jumlah bakteri Coliform sebanyak 8 X $10^{3}$ dan secara duplo diperoleh hasil $4 \times 10^{3}$. Sedangkan pada sampel BP jumlah bakteri Coliform sebanyak $8 \times 10^{3}$ dan secara duplo diperoleh hasil $5 \times 10^{3}$. Pada sampel $\mathrm{CP}$ jumlah bakteri Coliform sebanyak $10 \times 10^{3}$ dan secara duplo diperoleh hasil $2 \times 10^{3}$ Kemudian pada sampel AD jumlah bakteri Coliform sebanyak 6 X $10^{3}$ dan secara duplo diperoleh hasil $1 \times 10^{3}$. Pada sampel BD jumlah bakteri Coliform sebanyak $4 \times 10^{3}$ dan secara duplo diperoleh hasil $2 \times 10^{3}$. Dan pada sampel CD jumlah bakteri Coliform sebanyak $2 \times 10^{3}$ dan secara duplo diperoleh hasil $1 \times 10^{3}$. Semua hasil masuk dalam persyaratan Standar Nasional Indonesia Tahun 2006 tentang persyaratan mutu air minum dalam kemasan yaitu dibawah nilai $1,0 \times 10^{5} \mathrm{koloni} / \mathrm{g}$. Sehingga semua sampel memenuhi Syarat karena masuk ke dalam range persyaratan. Pemeriksaan Uji penduga dan uji penegas dan hasil pemeriksaan sebagai berikut :
Tabel 3. Hasil Uji Penduga Infused Water secara duplo.

\begin{tabular}{|c|c|c|c|c|c|c|c|c|c|c|c|c|}
\hline \multirow{3}{*}{$\begin{array}{c}\begin{array}{c}\text { Ino } \\
\text { kulu } \\
\mathrm{m}\end{array} \\
10 \mathrm{ml}\end{array}$} & \multicolumn{12}{|c|}{ Jumlah Tabung Positif } \\
\hline & \multicolumn{2}{|c|}{$\mathrm{AD}$} & \multicolumn{2}{|c|}{$\mathrm{BD}$} & \multicolumn{2}{|c|}{$\mathrm{CD}$} & \multicolumn{2}{|c|}{$\mathrm{AP}$} & \multicolumn{2}{|c|}{$\mathrm{BP}$} & \multicolumn{2}{|c|}{$\mathrm{CP}$} \\
\hline & 0 & 0 & 0 & 1 & 3 & 3 & 2 & 1 & 2 & 5 & 4 & 3 \\
\hline $1 \mathrm{ml}$ & 2 & 1 & 1 & 1 & 1 & 1 & 2 & 2 & 2 & 1 & 1 & 1 \\
\hline $0,1 \mathrm{ml}$ & 1 & 1 & 2 & 1 & 1 & 1 & 1 & 1 & 1 & 1 & 1 & 1 \\
\hline
\end{tabular}

Tabel 4. Hasil Uji Penegas Infused Water secara duplo.

\begin{tabular}{|c|c|c|c|c|c|c|c|c|c|c|c|c|}
\hline \multirow{3}{*}{$\begin{array}{c}\begin{array}{c}\text { Ino } \\
\text { kulu } \\
\mathrm{m}\end{array} \\
10 \mathrm{ml}\end{array}$} & \multicolumn{12}{|c|}{ Jumlah Tabung Positif } \\
\hline & \multicolumn{2}{|c|}{$\mathrm{AD}$} & \multicolumn{2}{|c|}{$\mathrm{BD}$} & \multicolumn{2}{|c|}{$\mathrm{CD}$} & \multicolumn{2}{|c|}{$\mathrm{AP}$} & \multicolumn{2}{|c|}{$\mathrm{BP}$} & \multicolumn{2}{|c|}{$\mathrm{CP}$} \\
\hline & 0 & 0 & 0 & 1 & 3 & 2 & 1 & 0 & 2 & 5 & 4 & 3 \\
\hline $1 \mathrm{ml}$ & 1 & 1 & 1 & 1 & 0 & 1 & 1 & 1 & 1 & 1 & 0 & 1 \\
\hline $0,1 \mathrm{ml}$ & 1 & 1 & 1 & 1 & 0 & 1 & 1 & 1 & 1 & 1 & 0 & 1 \\
\hline
\end{tabular}

Metode pemeriksaan coliform dengan Angka Paling Mungkin (APM) pada minuman Infused Water.

Tabel 5. Hasil Angka Paling Mungkin (APM) Coliform Infused Water

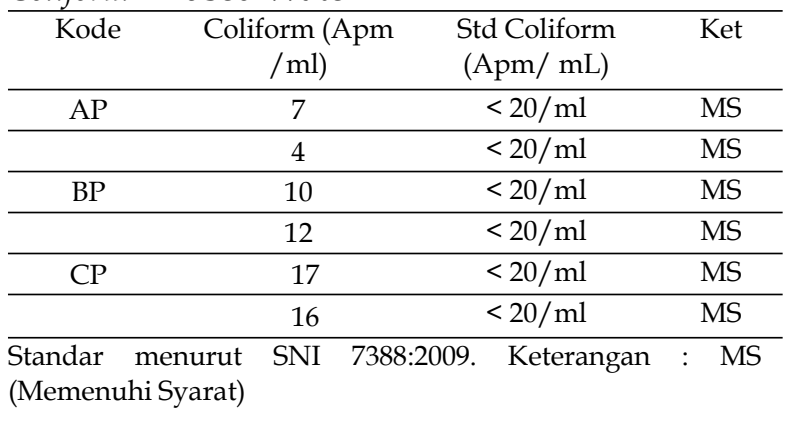

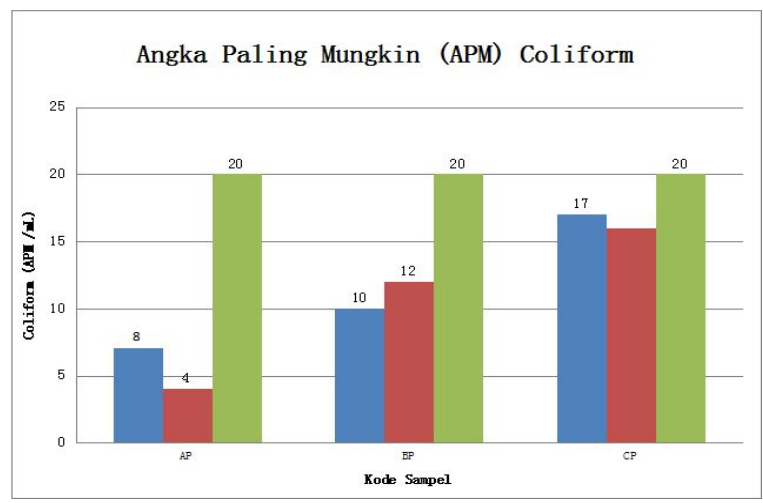

Grafik 3. Angka Paling Mungkin (APM) infused water yang disimpan pada suhu ruang $\left(25^{\circ} \mathrm{C}\right)$ 
Tabel 6. Hasil Angka Paling Mungkin (APM) Coliform Infused Water

\begin{tabular}{cccc}
\hline Kode & $\begin{array}{l}\text { Coliform } \\
(\text { Apm } / \mathrm{ml})\end{array}$ & $\begin{array}{l}\text { Std Coliform } \\
(\text { Apm } / \mathrm{ml})\end{array}$ & Ket \\
\hline $\mathrm{AD}$ & 4 & $<20 / \mathrm{ml}$ & MS \\
\hline & 4 & $<20 / \mathrm{ml}$ & MS \\
\hline $\mathrm{BD}$ & 4 & $<20 / \mathrm{ml}$ & MS \\
\hline & 7 & $<20 / \mathrm{ml}$ & MS \\
\hline $\mathrm{CD}$ & 9 & $<20 / \mathrm{ml}$ & MS \\
\hline & 10 & $<20 / \mathrm{ml}$ & MS \\
\hline
\end{tabular}

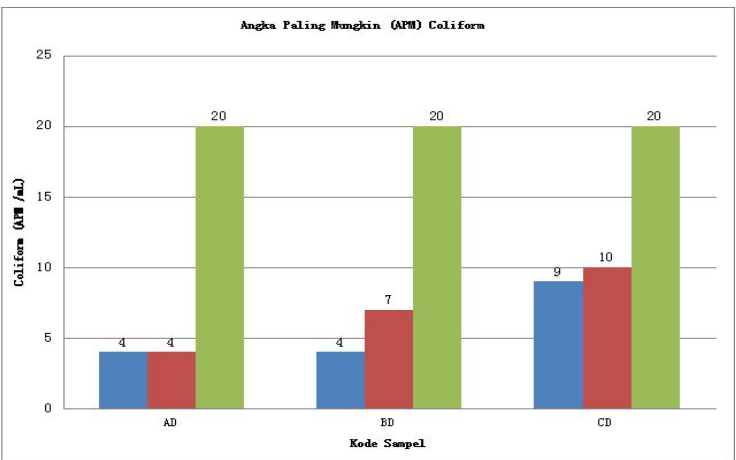

Grafik 4. Angka Paling Mungkin (APM) pada sampel infused water yang disimpan pada suhu refrigenerator $\left(5^{\circ} \mathrm{C}\right)$

Berdasarkan tabel 5 dan 6, dapat diketahui bahwa dari 6 sampel infused water yang diuji semunanya memenuhi syarat batas maksimal total bakteri coliform yang ditetapkan oleh SNI 7388:2009 tentang batas maksimum cemaran mikroba pada kategori minuman beralkohol, termasuk minuman serupa yang bebas alkohol atau rendah alkohol dengan batas maksimum yaitu $<20 / \mathrm{ml}$. Sampel dengan rata-rata bakteri coiform paling rendah adalah kode AD yaitu 4 $\mathrm{APM} / \mathrm{ml}$. Sampel dengan rata-rata bakteri coliform paling tinggi adalah kode $\mathrm{CP}$ yaitu 16,5 $\mathrm{APM} / \mathrm{ml}$.

Berdasarkan hasil penelitian yang telah dilakukan tentang Tingkat Keamanan minuman Infused Water dengan Diversifikasi Penyimpanan Yang Berbeda Sampel yang digunakan sebanyak 6 sampel, yaitu 3 sampel di suhu ruang dengan kode sampel AP, BP, CP sedangkan 3 sampel lagi di suhu dingin dengan kode sampel yaitu $\mathrm{AD}, \mathrm{BD}, \mathrm{CD}$. Dari 6 jenis sampel tersebut masing - msing dilakukan pemeriksaan kualitas mutunya yaitu dengan pemeriksaan hitung Angka Lempeng Total (ALT), dilanjutkan dengan uji penduga menggunakan media LB untuk mengetahui adanya bakteri coliform dalam sampel, kemudian dari hasil positif dari LB dilanjutkan dengan uji penegas menggunakan media BGLB (Briliant Green Lactose Broth).

Pada perhitungan koloni uji Angka Lempeng Total (ALT) setiap sampel hanya dihitung pengenceran dengan jumlah koloni antara 30 - 300. Hal ini bertujuan untuk memperkecil kemungkinan kesalahan dalam perhitungan. Dari 3 jenis sampel infused water yang disimpan dalam suhu ruang dan 3 jenis sampel yang disimpan dalam suhu dingin, jumlah bakteri semuanya masih dalam batas normal. Hasil ini berdasarkan SNI 01-3553-2006 tentang persyaratan mutu air minum dalam kemasan yaitu dibawah nilai 1,0 × $10^{5}$ koloni / g, artinya produk minuman infused water yang dijadikan bahan penelitian layak untuk dikonsumsi. Tingginya nilai Angka Lempeng Total menunjukkan banyaknya jumlah bakteri dalam suatu sampel. Nilai ALT tertinggi pada infused water kode CP (lemon, timun, daun mint) suhu ruang. Sedangkan nilai ALT terendah pada infused water kode CD (lemon, timun, daun mint) suhu dimgin.

Pada uji MPN, dilakukan uji penduga dan penegas. Pada uji penduga, digunakan media LB (Lactose broth). Media ini merupakan media untuk pemerkaya bakteri Coliform bukan bakteri Escherichia coli. Sehingga bakteri yang tumbuh pada media LB dapat bermacam-macam pada golongan koli. Selain itu media LB memiliki manfaat dan fungsi untuk masing-masing komponennya yaitu peptone dan beef extract. Kedua komponen tersebut merupakan sumber nutrisi esensial untuk metabolisme bakteri. Sedangkan fungsi dari Laktosa yaitu sumber Karbohidrat untuk bakteri melakukan fermentasi. Jika terbentuk gas, maka proses fermentasi telah terjadi sehingga membentuk kekeruhan pada dasar tabung dan hasilnya dinyatakan positif. Hal itu terjadi karena adanya bakteri coliform di dalam sample tersebut. Tetapi apabila tidak terbentuk gas, maka tidak terjadi proses fermentasi dan hasil tersebut diperoleh hasil negatif. Dari semua sampel dilakukan secara duplo, dapat diketahui bahwa pada 3 sampel yang ditempatkan pada suhu ruang dan dingin terdapat hasil positif. Hasil positif ditandai dengan terbentuknya gas pada tabung durham dan media LB berubah warna menjadi kuning dan keruh. Sampel yang menunjukkan adanya gas pada tabung durham ini dapat terjadi karena adanya bakteri yang dapat memfermentasi laktosa. Sehingga dapat diketahui bahwa terdapat bakteri Coliform pada sampel tetapi belum menentukan bakteri 
tersebut adalah bakteri E.coli dan sampel tersebut diperoleh hasil positif. Perlu diketahui bahwa bakteri Coliform terdiri dari Coliform Fekal dan Coliform Non Fekal, yang membedakan antara keduanya pada penelitian tersebut yaitu suhu inkubasi. Hasil yang positif adanya gas kemudian dilanjutkan pada tes media BGLB untuk memperkuat pertumbuhan dari bakteri Coliform (Nugroho, 2006).

Pada pemeriksaan media BGLB dilakukan pada suhu 37 C. Hasil yang di dapat pada media BGLB suhu 37 C, kandungan total rata rata Coliform pada sampel AP yaitu 6/ml, BP yaitu $11 / \mathrm{ml}$, CP yaitu $17 / \mathrm{ml}$, AD yaitu $4 / \mathrm{ml}$, BD yaitu $6 / \mathrm{ml}$, dan CD yaitu $10 / \mathrm{ml}$. Hasil ini untuk mengetahui banyaknya Coliform non fecal pada setisp sampel. Dari setiap sampel diketahui bahwa jumlah Berdasarkan standar acuan SNI 7388:2009 tentang batas maksimum cemaran mikroba pada kategori minuman beralkohol, termasuk minuman serupa yang bebas alkohol atau rendah alkohol dengan batas maksimum yaitu $20 / \mathrm{ml}$. Hasil ini menunjukkan bahwa hasil penelitian minuman dengan produk infused water masih layak dikonsumsi.

\section{Simpulan dan Saran}

Berdasarkan hasil penelitian tingkat keamanan minuman infused water dengan diversifikasi penyimpanan yang berbeda menunjukkan bahwa :

1. Hasil hitung Angka Lempeng Total (ALT) pada sampel minuman infused water yang disimpan suhu refrigenerator lebih sedikit dibandingkan sampel infused water yang di simpan di suhu ruang yaitu dibawah nilai standar $\left(1,0 \times 10^{5} \mathrm{koloni} / \mathrm{g}\right)$

2. Hasil nilai MPN pada sampel minuman Infused water pada suhu refrigenerator lebih sedikit dibandingkan pada sampel infused water yang disimpan di suhu ruang yaitu dibawah nilai standar $(\leq 20 / \mathrm{ml})$.

3. Hasil hitung Angka Lempeng Total (ALT) pada sampel minuman infused water masih memenuhi standar SNI 01-3553-2006 Dan hasil nilai MPN pada sampel minuman Infused water yang telah diteliti memenuhi standar acuan SNI 7388 : 2009

Berdasarkan hasil penelitian tingkat keamanan minuman infused water dengan diversifikasi penyimpanan yang berbeda menunjukkan bahwa
1. Bagi peneliti : Perlu dilakukan penelitian lebih lanjut terhadap jenis sampel serupa dengan variasi lamanya waktu penyimpanan untuk mengetahui tingkat ketahanan suatu produk minuman yang layak untuk dikonsumsi.

2. Bagi masyarakat: Minuman infused water menggunakan buah lokal dan proses pembuatannya sangat mudah tetapi harus memperhatikan higiene perorangan, bahan baku dan peralatan yang akan digunakan.

\section{Ucapan Terima Kasih}

Bapak Sugiyanto, S.Pd, M.App,Sc selaku Direktur Poltekkes Kemenkes Semarang. Bapak SY. Didik Widiyanto, SKM, M.Kes selaku ketua Jurusan Analis Kesehatan Poltekkes Kemenkes Semarang. Ibu Nina Indriyawati, MNS selaku Ka. Unit Penelitian dan Pengabdian kepada Masyarakat (UPPM) Poltekkes Kemenkes Semarang.

\section{Daftar Pustaka}

Andrian G. Bambang1), Fatimawali1), dan Novel, S. Kojong, 2014. Analisis Cemaran Bakteri Coliform Dan Identifikasi Escherichia Coli Pada Air Isi Ulang Dari Depot Di Kota Manado Jurnal Ilmiah Farmasi - UNSRAT Vol. 3 No. $3: 325$

Andrian G, Bambang , dkk. 2014. Analisis Cemaran Bakteri Coliform dan Identifikasi Eschirichia coli pada Air Isi Ulang dari Depot di Kota Manado. Manado : Jurnal Ilmiah Farmasi UNSRAT.

Badan Standarisasi Nasional. 2009.Batas Maksimum Cemaran Mikroba dalam Pangan. BSN.Jakarta.

Dwidjoseputro, D. 2010. Dasar-Dasar Mikrobiologi. Jakarta: djambatan.

Hartini, P. B. (2011). Studi Keamanan Mikrobiologi Makanan Jajanan Di Kantin FalesaIPB. Bogor: IPB.

Hardianto, I Gusti Ketut Suarjana, Mas Djoko Rudyanto, 2012. Pengaruh Suhu dan Lama Penyimpanan terhadap Kualitas Telur Ayam Kampung Ditinjau dari Angka Lempeng Total Bakteri, Indonesia Medicus Veterinus 1(1) : 71-84

Isnawati. 2012. Hubungan Higiene Sanitasi Keberadaan Bakteri Coliform dalam Es Jeruk di Warung Makan Kelurahan 
Tembalang Semarang. Jurnal Kesehatan Masyarakat. No.2. Vol.1. Hal 1005-1017

Juwita, M dan T. Sudartini. 2007. Pertumbuhan dan Hasil Mentimun(Cucumis sativus L.) Varietas Venus pada Frekuensi dan Konsentrasi Mikroba Efektif yang Berbeda. Jurnal Penelitian Bidang Ilmu Pertanian. Universitas Siliwangi Tasikmalaya2 (1): 1724

Lestari, Dyah Puji., Nurjazuli dan Hanani, Yusniar. 2015. Hubungan Higiene Penjamah dengan Keberadaan Bakteri Escherichia coli pada Minuman Jus Buah di Tembalang. Jurnal Kesehatan Lingkungan Indonesia. No.1. Vol.4.

$\mathrm{Ni}$ Luh Payastiti Yunita, Ni Made Utami Dwipayanti, 2010, Kualitas Mikrobiologi Nasi Jinggo Berdasarkan Angka Lempeng Total, Coliform Total Dan Kandungan Escherichia Coli Jurnal Biologi Volume XIV No.1

Radji, Maksum. 2010. "Buku Ajar Mikrobiologi : Paduan Mahasiswa Farmasi dan Kedokteran". Jakarta: EGC

Sahdan, Nona. (2010). Analisis Bakteri Coliform Pada Jajanan Anak Sekolah SD InpresBontomanai Makassar. Skripsi. Jurusan Biologi UIN Alauddin Makassar:

SNI. 2009. Minuman Beralkohol, Termasuk Minuman Serupa Yang Bebas Alkohol atau rendah Alkohol, Standar Nasional Indonesia, SNI-7388:2009, Badan Standar Nasional.

Wijoyo, P.M. 2012. Budidaya Mentimun yang Lebih Menguntungkan. Jakarta: PT Pustaka Agro Indonesia, hal :69 